\title{
PERENCANAAN MASJID SUMEDANG
}

\author{
Annisa $^{1}$, Ilham ${ }^{1}$, Yogi Sirodz Gaos ${ }^{2}$ dan Irvan Wiradinata ${ }^{2}$ \\ ${ }^{1}$ Institut Teknologi Sains Bandung \\ ${ }^{2}$ Universitas Ibn Khaldun Bogor \\ E-mail: annisa@itsb.ac.id
}

\begin{abstract}
ABSTRAK. Dalam perencanaan pembangunan, perencanaan arsitektur dan struktur merupakan aspek penting yang harus dikaji. Aspek arsitektur ditinjau agar kenyamanan dalam tata ruang dan estetika dapat terpenuhi. Sedangkan aspek struktur dikaji agar bangunan tersebut mampu menahan beban rencana. Kegiatan ini bertujuan untuk membuat gambar rencana pembangunan sarana ibadah masjid secara layak. Metode yang digunakan dalam kegiatan pengabdian berupa analisis desain perencanaan arsitektur dan struktur. Bangunan yang direncanakan adalah sarana ibadah masjid. Lokasi masjid akan dibangun di atas tanah hibah yang terletak di Jalan Raya Tampomas, Kecamatan Sumedang Utara. Pengumpulan data dilakukan dengan observasi dan wawancara. Studi literatur digunakan untuk mencari teori terkait perencanaan pembangunan dari aspek aristektur dan struktur. Data dianalisis dengan pendekatan tata ruang dan struktur beton bertulang. Hasil kegiatan pengabdian ini berupa dokumen perencanaan.
\end{abstract}

Key words: Masjid; Perencanaan; Pembangunan

\begin{abstract}
Architecture and structure planning are major aspect to be considered in construction development. Architecture planning is examined to achieve a good aestethic and layout. Struture planning is calculated to withstand the structure load. The aim of this activity is to design a mosque properly. Method used in this activity is using architecture and structure approach. The planned building is a mosque worship facility. The location of the mosque will be built on grant land located on Jalan Raya Tampomas, North Sumedang District. Data was collected by observation and interview. Literature study is used to find theories related to development planning from the architectural and structural aspects. Data were analyzed using spatial approach and reinforced concrete structures. The results of these service activities in the form of a planning document.
\end{abstract}

Key words: Mosque; Planning; Construction

\section{PENDAHULUAN}

Perencanaan pembangunan merupakan suatu proses yang terdiri dari tahapan-tahapan yang dalam pelaksanaannya memanfaatkan sumberdaya untuk mencapai suatu tujuan dalam batasan ruang lingkup pekerjaan, biaya, mutu dan waktu (Kerzner, 2017; Annisa et al., 2019; PMBOK, 2016). Dalam proses perencanaan pembangunan, melibatkan berbagai unsur diantaranya bidang keilmuan arsitektur dan struktur. Perencanaan pembangunan yang baik bertujuan agar pada tahap operasi, bangunan yang direncanakan terasa nyaman dan aman. Oleh karena itu perlu dikaji secara arsitektur dan struktur.

Kegiatan ini bertujuan untuk membuat perencanaan pembangunan sarana ibadah Masjid di KabupatenSumedang Utara dikavling seluas $\pm 514 \mathrm{~m}^{2}$ yang diwakafkan oleh salah satu penduduk setempat. Kecamatan Sumedang Utara merupakan salah satu bagian dari Kabupaten Sumedang. Kecamatan Sumedang Utara memiliki populasi sebanyak 107.405 jiwa, dengan laju pertumbuhan tertinggi di Kabupaten Sumedang dengan nilai 0,74\%. Sebanyak 97\% dari peduduk di Kecamatan Sumedang Utara ini beragama Islam (BPS, 2019). Berdasarkan laju pertumbuhan yang tinggi dan mayoritas penduduk beragama Islam, maka dibutuhkan pertambahan sarana ibadah di Kecamatan Sumedang Utara.

\section{METODE}

Kegiatan pengabdian ini berupa jasa konsultansi kegiatan perencanaan pembangunan masjid yang akan didirikan di atas tanah waqaf yang terletak di Jalan Tampomas, Kecamatan Sumedang Utara, Kabupaten Sumedang. Pengumpulan data dimulai dari wawancara dan diskusi dua arah mengenai konsep atau ide awal dan rencana desain untuk mendapatkan persepsi dan ekspektasi dari pemilik lahan tentang rencana pembangunan masjid. Sumber data primer berupa dokumen site plan. Observasi di lapangan dilakukan untuk analisis tapak lokasi rencana masjid, kondisi lingkungan sekitar dan observasi facade bangunan masjid yang dijadikan referensi. Kajian pustaka digunakan sebagai pendukung konsep perencanaan bangunan masjid. Metode analisis data yang digunakan adalah metode pendekatan ruang, tapak dan zoning yang biasa digunakan dalam perencanaan desain, serta analisis perhitungan struktur dengan konsep beton bertulang.

\section{HASIL DAN PEMBAHASAN}

Tahapan kegiatan terdiri dari beberapa kegiatan, yaitu: (1) tahap konsep, (2) observasi dan (3) perancangan.

1. Konsep

Tahap awal kegiatan konsultasi adalah tahap 
konsep berupa wawancara dan diskusi dua arah dengan pemilik mengenai ide, rencana, persepsi dan ekspektasi peruntukan bangunan yang akan direncanakan dibangun di atas kavling. Dari hasil konsultasi pada tahap ini ditetapkan peruntukan kavling untuk kegiatan keagamaan yaitu pembangunan sarana ibadah masjid. Gambar 1 merupakan dokumen yang di dapat sebagai data awal acuan desain. Dokumen tersebut berupa gambar kavling rencana pembangunan masjid.

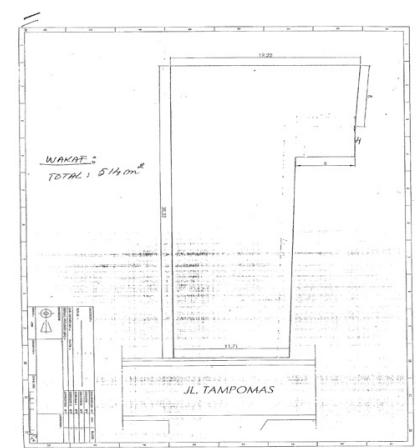

Sumber: Dokumentasi Pribadi

\section{Gambar 1. Gambar Kavling}

2. Observasi Lapangan

Tinjauan ke lapangan dilakukan untuk pendataan dan pengukuran kavling, melihat kondisi kavling, batas-batas kavling, kondisi listrik, air, saluran kota, aksesibilitas, arah kiblat, cuaca, dll. Kavling berada di lahan seluas $514 \mathrm{~m}^{2}$ yang berlokasi di Jalan Tampomas, Desa Kotakaler. Letak kavling terhadap arah kiblat adalah serong sehingga orientasi bangunan berbeda dengan arah kiblat. Bangunan masjid di rencanakan satu lantai. Dikarenakan posisi lahan berada langsung menghadap jalan utama diperlukan area parkir, sehingga memberikan banyak akses kemudahan masyarakat maupun pelaku perjalanan yang melewati area tersebut. Dari hasil kegiatan ini didapat dokumentasi berupa foto, video, data pengukuran yang dijadikan dasar proses analisis pra desain. Gambar situasi dan kondisi kavling eksisiting dapat dilihat pada gambar 2.

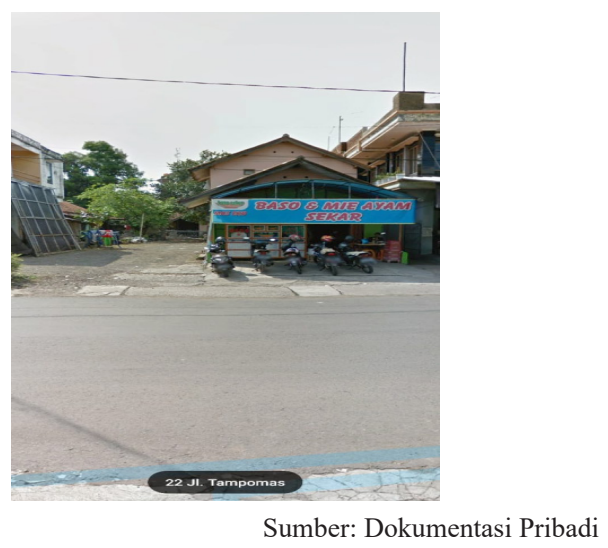

Gambar 2. Kondisi Eksisting Kavling

3. Perancangan

Secara arsitektur langkah analisis pertama adalah analisis ruang mencakup identifikasi aktivitas yang akan diakomodir, kebutuhan ruang, standar ruang dan program ruang. Selanjutnya dilakukan penyusunan zona dan sirkulasi berbagai kebutuhan ruang yang telah direncanakan agar sesuai dengan tuntutan dan kebutuhan desain (Wibawa et al., 2016). Hasil desain layout ruangan dapat dilihat pada gambar 3. Struktur bangunan direncanakan dengan meng-gunakan material beton bertulang. Berdasarkan SNI Beton (SNI 2847-2013), bangunan masjid direncanakan dengan sistem struktur dasar penahan lateral dengan Sistem Rangka Pemikul Momen Khusus (SRPMK).

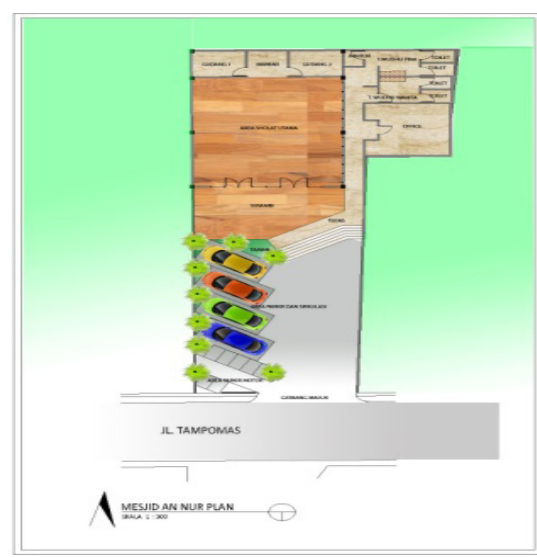

Sumber: Dokumentasi Pribadi

Gambar 3. Layout Arsitektur

Berdasarkan SNI Gempa (SNI 1726-2012), bangunan masjid terletak di kategori desain seismik A,B. Faktor modifikasi respons (R) yang digunakan adalah 8 . Performa kriteria di desain dengan beban gempa 500 tahun (FEMA 451 B) sehingga level kinerja yang ditargetkan adalah immediate occupancy. Pihak pemilik gedung harus mengetahui kondisi gedungnya sehingga dapat mengestimasi kerusakan atau besarnya biaya perbaikan yang harus dikeluarkan apabila terjadi gempa. Kondisi bangunan apabila terjadi gempa akan terjadi kerusakan kecil atau tidak berarti pada struktur, sedangkan kekakuan struktur hampir sama pada saat belum terjadi gempa. Pembebanan struktur mengacu pada SNI Beton 2013, SNI Gempa 2012 dan SNI Pembebanan Minimum Gedung 2013. Hasil perencanaan struktur dapat dilihat pada gambar 4 .

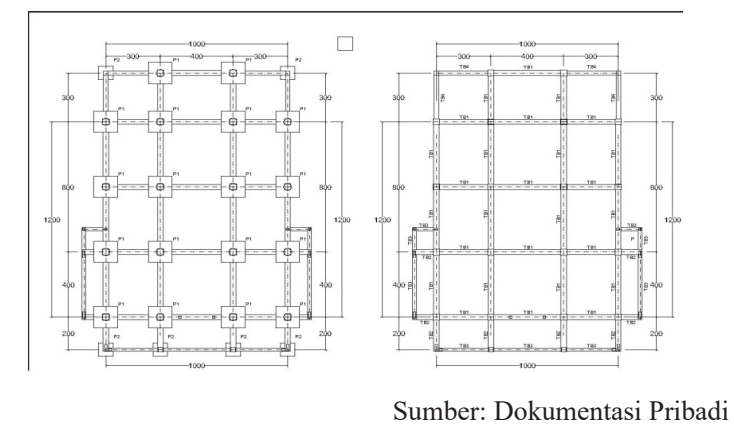

Gambar 4. Denah Pembalokan 


\section{SIMPULAN}

Hasil analisis konsultasi rencana kegiatan pembangunan berupa dokumen perencanaan masjid tahap awal. Terdiri dari gambar arsitektur dan struktur. Gambar arsitektur berupa denah pembagian ruang dan tampak, sedangkan gambar struktur berupa denah pondasi, denah pembalokan dan denah kolom.

\section{UCAPAN TERIMAKASIH}

Penulis mengucapkan terimakasih kepada yayasan Institut Teknologi Sains Bandung dan PT. Intan Prima Kalorindo yang telah memfasilitasi kegiatan ini.

\section{DAFTAR PUSTAKA}

Annisa, A. (2019). Manajemen Komunikasi Proyek: Studi Kasus Perusahaan Berbasis Engineering, Procurement, Construction dan Manufacturing (EPCM) Kawasan Industri Jababeka Cikarang. Planners Insight: Urban and Regional Planning Journal, 2(1), 026-034.

Indonesia, S. N. (2013). Beban minimum untuk perancangan bangunan gedung dan struktur lain. Badan Standarisasi Nasional. Bandung.
Kerzner, H. (2017). Project management: a systems approach to planning, scheduling, and controlling. John Wiley \& Sons.

Nasional, B. S. (2012). Tata Cara Perencanaan Ketahanan Gempa Untuk Struktur Bangunan Gedung dan Non Gedung SNI 1726: 2012. Jakarta: BSN.

Nasional, B. S. (2013). Persyaratan beton struktural untuk bangunan gedung (SNI 2847: 2013). Jakarta: Standar Nasional Indonesia.

Project Management Institute. (2000). A guide to the project management body of knowledge (PMBOKguide)(Vol.7). Project Management Inst.

Sumedang, B. K. (2018). Kecamatan Sumedang Utara dalam Angka Tahun 2018.

Sumedang, B. K. (2019). Kabupaten Sumedang dalam Angka Tahun 2019.

Symans, M. D. (2017). Instructional Material Complementing FEMA 451.

Wibawa, B.A.,\& Saraswati,R.S.(2016). Perencanaan Pembangunan Masjid Al-Ikhwan Kelurahan Karangayu, Semarang. E-Dimas: Jurnal Pengabdian kepada Masyarakat, 7(1), 1-14. 